\title{
New Formulations of Flame-retardant Flexible Polyvinylchloride Composites
}

\begin{abstract}
ALINA ELENA COMAN ${ }^{1,2}$, AUGUSTA RALUCA GABOR ${ }^{1}$, SERGIU STOIAN ${ }^{1}$, CRISTIAN ANDI NICOLAE ${ }^{1}$, VALENTIN RADITOIU IOANA CATALINA GIFU' ${ }^{1}$, TANTA VERONA IORDACHE*, GHEORGHE HUBCA*

'Polymers Department- National Institute for Research \& Development in Chemistry and Petrochemistry-ICECHIM, 202 Splaiul Independentei, 060021, Bucharest, Romania

2University Politehnica of Bucharest, Faculty of Applied Chemistry and Materials Science, Advanced Polymer Materials Group, Bucharest, 1-7 Polizu Str., 011061, Bucharest, Romania

The composition of electrical wires and cables is of critical importance in controlling fire risks. In this respect, polyvinylchloride (PVC) composites are extensively used. Yet, PVC composites are multiple systems in which the final properties depend on the nature and size of the reinforcement or flame-retardant agent and the type of lubricant used for their preparation. Thereby, in this study two series of PVC composites, with stearic acid and calcium stearate as lubricants were prepared in parallel, and additivated with various commercial minerals as reinforcement/flame retardant agents, such as calcium carbonate, alumina trihydrate (ATH) and $\mathrm{HMH}$ (a mineral of hydromagnesite and huntite). Following the structure (by FT-infrared), thermal behavior (thermal analyses and differential scanning calorimetry) and mechanical properties (dynamic mechanical analyses, tensile strength and elongation at break) of PVC composites, the flameretardant effect of the selected minerals was investigated by measuring the limiting oxygen index (LOI). Only ATH and HMH-based composites presented higher flame-resistance, relative to the control samples, making them suitable for the proposed application. The contact angle was evaluated for determining the hydrophobicity of composites when using ATH or HMH, to get an opinion about the stability of the materials in moist environments. Finally, SEM was used to determine the homogeneity of PVC samples.
\end{abstract}

Keywords: PVC, alumina trihydrate, Ultracarb, stearic acid, calcium stearate, flame retardant

PVC is the third most used thermoplastic, after polyethylene and polypropylene. PVC is a versatile polymer and has been widely used because of its low production cost, electrical protecting properties and good insulation performance, chemical and fire resistance, and also high abrasion resistance.

In this context, flexible PVC is intensively used as covering insulation for electrical and communication cables, while rigid PVC is used in domestic applications, such as window frames, doors, profiles and sidings because of its high level of combustion resistance.

PVC, when heated at temperatures above $140{ }^{\circ} \mathrm{C}$ releases smoke and toxic gases like hydrogen chloride $(\mathrm{HCl})$ due to dehydrochlorination reactions. Hence, obtaining PVC composites with flame retardant and smoke suppression properties has received an increasing interest during the past decades. Rigid PVC composites do not contribute to fire propagation due to high contents of chlorine ( $56.8 \%$ ), and thus, passes the flammability test without adding flame retardants additives. For flexible PVC composites on the other hand, flame retardant agents must be used because the plasticizer content reduces the resistance to fire [1-4]. In this respect, reinforcing or flame retardant agents or fillers are also used in PVC systems to reduce formulation costs and improve the electrical insulation properties. Moreover, fillers are carefully chosen due to the significant impact upon the composite system, i.e. increased tensile strength and thermal stability and reduced costs [5]. Common filler materials include calcium carbonate of different sizes, kaolin, aluminium hydroxide (or alumina trihydrate), magnesium hydroxide, mica, silica, talc.

When PVC composites are exposed to fire, they decompose and the chlorine content is converted to hydrogen chloride gas, which can be released in the vapour state. Because this gas is toxic it should better remain in the condensed phase. This can be accomplished by adding calcium carbonate in the system, for example, to form calcium chloride [6]. The calcium carbonate particles can capture the emitted $\mathrm{HCl}$ and minimise the corrosivity of the smoke, if used as filler; and, hence, acting like a thermal stabilizer [7-8]. Such action also prevents the early PVC decomposition into conjugated polyenes. This latter process is the resultof a zipper dehydrochlorination process catalyzed by hydrochloric acid $[3,6]$.

Alumina trihydrate (noted ATH) is highly used in the thermoplastics industries as a flame retardant and smoke suppressant. The major interest for ATH refers to the water content, about $34.6 \% \mathrm{H}_{2} \mathrm{O}$ by weight. This intramolecular water is endothermically released at over $200{ }^{\circ} \mathrm{C}$. This means that the heat need for volatilizing the side-products is used for releasing the intramolecular water form ATH. Hence, less heat is accessible to decomposing the polymer components that feed the combustion. In this case, ATH acts as a heat sink when the composites are exposed to fire. Furthermore, ATH increases the char formation in the polymer and a protective layer made up of aluminum oxide and carbonized products are formed on the surface of the polymer, hindering the smoke release upon combustion. Therefore, it can be noted that ATH works both as flame retardant and as smoke suppressant. As a result, the loading of ATH in flexible PVC formulations usually ranges between 20 to $50 \mathrm{phr}$ (parts per hundred resins, base polymer $=$ PVC) to decrease the heat release rate and delay the time to ignition as much as possible [8-10]. The two synergistical effects also improve the limiting oxygen index (LOI). The relative flammability characteristics of

* email: iordachev.icechim@gmail.com,Phone: +40755159896; gheorghe_hubca@yahoo.com,Phone: +40744754210 
polymeric materials are determined by LOI. The higher the LOI values the greater the resistance of the material to burning (more fire retardant). In this work the targeted values for $\mathrm{LOI}$ are beyond the threshold of $21 \%$ from where the composites can be classified as flame resistant [1113].

Another mineral used as flame retardant is a mixture of two minerals: huntite and hydromagnesite $(\mathrm{HMH}$, or Ultracarb as commercial product). It is used particularly in the wire and cable industries and for rubber applications as an alternative to the more expensive ATH. Each of the two minerals, i.e. hydromagnesite and huntite ( $\mathrm{HMH})$, are flame retardants and mixing them leads to new products with special properties for various applications. $\mathrm{HMH}$ has a unique 3-stage fire retardant mechanism. While the common endothermic flame-retardant fillers act by releasing water in a single process, HMH works as follows: at temperatures of $\sim 220^{\circ} \mathrm{C}$ begins the thermal decomposition and releases water. Ataround $330^{\circ} \mathrm{C}, \mathrm{CO}_{2}$ is released and at temperatures above $560{ }^{\circ} \mathrm{C} \mathrm{HMH}$ particles accumulate at the surface of the burning PVC composites and form a stable char. This final step leads to the hindering of the combustion process and implicitly the propagation of the fire $[9,14-17]$.

Considering the present literature, this paper provides an interesting comparative study upon the influence of calcium carbonate with particle size of 1 and $2 \mathrm{~mm}$, of ATH and HMH as fillers, and the influence of stearic acid and of calcium stearate, as lubricants upon the thermal, the mechanical, the structural and the flame resistance properties of novel PVC composite formulations with potential applications in the industry for electrical wires and cables.

\section{Experimental part \\ Materials}

For this research the used materials included PVC Ongrovil S5070 from BorsodChem (K-value 70.4), diisononyl phthalate (DINP) as plasticizer (LG Chem), CaZn salt as heat stabilizer (Baeropan MC $91446 \mathrm{KA} / 3$, Baerlocher), calcium carbonate particles of $1 \mu \mathrm{m}$ and 2 $\mu \mathrm{m}$ (noted V01 and V02, respectively) as reinforcing agent (Omya Calcita), Martinal ATH OL-104 LEO (Huber) and HMH (Ultracarb, LKAB Minerals) as flame retardants, stearic acid (Stera Chemicals) and calcium stearate as lubricants (Bridgexim).

\section{Preparation of PVC composites}

The test specimens were prepared using an industrial methodology, as follows: first, the samples were prepared by melting and mixing PVC with the plasticizer, the heat stabilizer, lubricant and reinforcing agent/flame retardant. Afterwards, the specimens were blended into a two-roll mill at $160{ }^{\circ} \mathrm{C}$ for $20 \mathrm{~min}$, followed by compression at 170 ${ }^{\circ} \mathrm{C}$ to form sheets with dimension $150 \times 150 \times 1 \mathrm{~mm}^{3}$. The compositions of all of the samples are listed in table 1 . All the samples, except samples 2 and 3 which are not filled, have the following formulation: PVC 100 phr, DINP 60 phr, inorganic filler $40 \mathrm{phr}$, lubricant $0.5 \mathrm{phr}$ and heat stabilizer agent 4 phr. DINP used as plasticizer provides compound flexibility, which improved viscosity and processability [1819]. This type of phthalate plasticizer behaves like solvents but is not chemically bounded to PVC. The DINP physically bounds PVC by weak electrostatic interactions as the result of heating process during composites manufacturing.

Sample 1 of stabilized PVC and lubricant alone, prepared as a control sample, degraded during the preparation process having a brown-reddish colour and being very brittle. Therefore, these samples could not be analysed and the results were compared with the control samples 2 and 3, which contain stabilized PVC, lubricant and plasticizer (i.e. sample 2 with stearic acid and sample 3 with calcium stearate).

Table 1

FORMULATIONS CONTAINING DIFFERENT TYPES OF INORGANIC FILLER (REINFORCING/FLAME RETARDANT AGENTS) AND LUBRICANT

\begin{tabular}{|c|c|c|}
\hline Sample code & $\begin{array}{c}\text { Inorganic } \\
\text { filler }\end{array}$ & Lubricant \\
\hline $\mathbf{2}$ & - & Stearic acid \\
\hline 4 & VO2 & Stearic acid \\
\hline $\mathbf{5}$ & VO1 & Stearic acid \\
\hline $\mathbf{8}$ & ATH & Stearic acid \\
\hline 10 & HMH & Stearic acid \\
\hline $\mathbf{3}$ & - & Calcium stearate \\
\hline $\mathbf{6}$ & VO2 & Calcium stearate \\
\hline $\mathbf{7}$ & VO1 & Calcium stearate \\
\hline $\mathbf{9}$ & ATH & Calcium stearate \\
\hline 11 & HMH & Calcium stearate \\
\hline
\end{tabular}

*All the samples, except samples 2 and 3, which are not filled, have the following formulation: PVC 100 phr, DINP 60 phr, inorganic filler $40 \mathrm{phr}$, lubricant $0.5 \mathrm{phr}$ and stabilization agent $4 \mathrm{phr}$

Infrared spectroscopy analysis (FTIR)

Molecular structure of PVC based composites were analyzed using an infrared spectrometer type JASCO FT/ IR 6300 Specac Golden Gate ATR with diamond in transmission mode. The measured range was $400-4000$ $\mathrm{cm}^{-1}$.

\section{Thermogravimetric analysis (TGA)}

The thermogravimetric analysis were performed on a thermogravimetric analyzer (Q5000IR, TA Instruments) at a heating rate of $10^{\circ} \mathrm{C} \mathrm{min}-1$ under a nitrogen atmosphere or air. Samples of approximately 8 - 14 mg were analyzed in the $40-700{ }^{\circ} \mathrm{C}$ temperature range.

\section{Differential scanning calorimetric analysis (DSC)}

Differential scanning calorimetry (DSC) experiments were carried out using DSC Q2000 from TA Instruments, working in temperature-modulated mode (MTDSC) with dynamic purge gas (helium $99.99 \%$ with flow rate $25 \mathrm{~mL}$ $\mathrm{min}^{-1}$, modulated scan). Approximately, $25-30 \mathrm{mg}$ samples were weighted and heated from -110 to $155^{\circ} \mathrm{C}$ with a heating rate of $20^{\circ} \mathrm{C} \mathrm{min}-1$.

\section{Dynamic mechanical analysis (DMA)}

Dynamic mechanical analysis (DMA) experiments were carried out using DMA Q800 from TA Instruments, module DMA Multi-Frequency-Strain, in the tension mode, obtaining thermal behaviours of the PVC based composites, through the temperature ramp method. The sample size was 13.5 $\times(6.4-7) \times(0.77-0.79) \mathrm{mm}$ and the heating rate was $5^{\circ} \mathrm{C}$ $\mathrm{min}^{-1}$ from -75 to $105^{\circ} \mathrm{C}$.

As a result of the experiments, the temperature dependences of the elastic shear modulus (E2), shear losses (E3) and the mechanical loss tangent $(\operatorname{tg} \delta$ ) of the investigated PVC composites were extracted. 

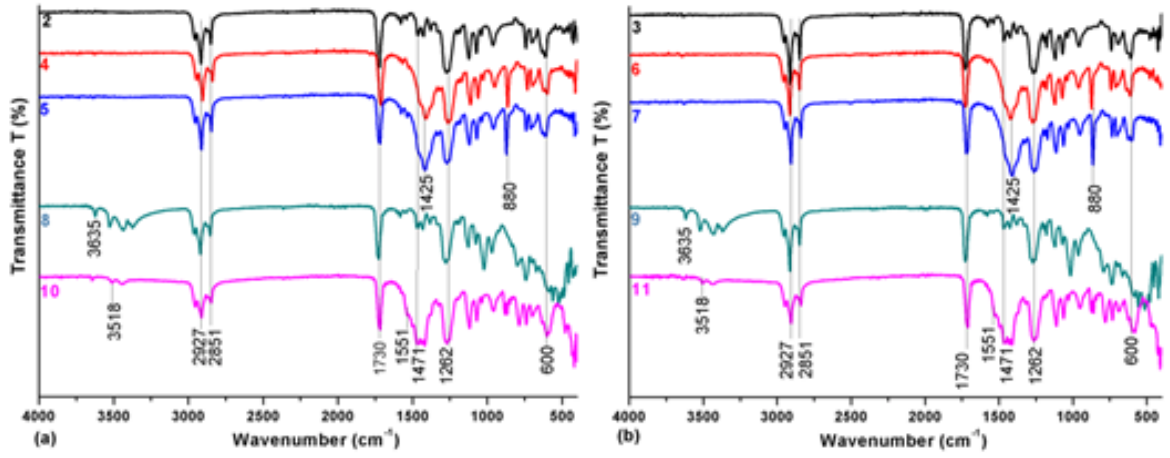

Fig.1. Infrared spectra of PVC based composites with and without filler: a) PVC composites based on stearic acid as lubricant and b) PVC composites based on calcium stearate
Tensile strength and elongation at break

The tensile strength and elongation at break of the samples were performed on a computer-controlled electronic tensile testing machine (Instron 3382) with a constant speed of $100 \mathrm{~mm} \mathrm{~min}^{-1}$ at room temperature.

\section{Limited oxygen index (LOI)}

The limited oxygen index (LOI) index was tested using a Stanton Redcroft FTA Flammability Unit instrument. The test specimens were $120 \times 60(\mathrm{~L} \times \mathrm{W}) \mathrm{mm}$ in dimension.

\section{Contact angle (CA)}

The Drop Shape Analysis System, model DSA1 (FM40 Easy Drop) from KRÜSS GMbH was used to measure the static contact angle of deionised water on deposited films, at room temperature in air. The sample was placed on a plane stage, using a stainless steel needle with outer diameter of $0.5 \mathrm{~mm}$. All CA measurements were carried out in static regime at room temperature, with a drop volume of $6 \mu \mathrm{L}$. Contact angles were obtained by fitting the drop shape with a mathematical expression and then calculating the slope of the tangent to the drop at the liquidsolid-vapour (LSV) interface. The CA values were averaged over 5 measurements on different drops.

\section{Scanning electronic microscopy (SEM)}

Scanning electronic microscopy (SEM) was used to study the morphology and homogeneity of the PVC samples. Vega-3 (Tescan, Brno, Czech Republic) apparatus in high vacuum mode with working distances in the range of 4-8 $\mathrm{mm}$ and an acceleration voltage of $5 \mathrm{kV}$ was used. Before examination, the samples were coated with a thin layer of gold with a gold coater (Quorum Q 150 RS; Quorum Technologies, Lewes, UK).

\section{Results and discussions \\ FTIR analysis}

The transmission mode was applied to obtain the spectra for PVC composites- samples 2 and 3 considered control samples. The two spectra are similar because the main difference is represented by the lubricanttype (stearic acid or calcium stearate). Figure 1. $a$ and b shows the characteristic bands of PVC, plasticizer and the two lubricants. In the both spectra the $\mathrm{CH}$ and $\mathrm{CH}_{\text {, }}$ bands from the PVC backbone are present at 2851 and $2927 \mathrm{~cm}^{-1}$. PVC characteristic band attributed to $\mathrm{C}-\mathrm{Cl}$ bond appeared at $600 \mathrm{~cm}^{-1}$. The band from $1730 \mathrm{~cm}^{-1}$, corresponding to $\mathrm{C}=0$ vibrations is attributed to the lubricant (aliphatic carboxyl) and phthalate plasticizer (aromatic carboxyl). Carbocatenary long chain ( $\mathrm{CH}$ and $\mathrm{CH}_{2}$ bonds) of the plasticizer and of the lubricants are overlapping with those of PVC at 2851 and $2927 \mathrm{~cm}^{-1}$ and at 1262 and $1471 \mathrm{~cm}^{-1}$ the vibrations of $\mathrm{C}-\mathrm{O}$ groups from the lubricant (aliphatic carboxyl) and phthalate plasticizer (aromatic carboxyl) were observed. Figure 1. $a$ and $b$ also depicts the spectra of PVC based composite with filler (i.e. flame-retardant agents). From it, the presence of additional bands corresponding to the incorporated fillers was observed. Samples with the two types of calcium carbonate V01 and V02 (i.e. samples 4,5 with stearic acid as lubricantfig.1. a and samples 6,7 with calcium stearate as lubricantfig. 1. b), display specific bands around $880 \mathrm{~cm}^{-1}$ attributed to $\mathrm{Ca}-\mathrm{O}$ vibrations, and bands from $1425 \mathrm{~cm}^{-1}$ corresponding to $\mathrm{C}-\mathrm{O}$ group from carbonate structure.

The presence of ATH in the PVC composites (sample 8 with stearic acid as lubricant -fig.1. a and sample 9 with calcium stearate as lubricant -fig.1. b) is demonstrated by the band corresponding to hydroxyl group at $3635 \mathrm{~cm}^{-1}$. Further on, for the PVC composites with HMH inorganic filler (sample 10 with stearic acid as lubricant-fig.1. a and sample 11 with calcium stearate as lubricant -fig.1. b) the bands observed at $3518 \mathrm{~cm}^{-1}$ belong to $-\mathrm{OH}$ group from hydromagnesite. Here as well, the band of anion corresponding to the huntite is displayed at around 1551 $\mathrm{cm}^{-1}$.

\section{Thermogravimetric analysis (TGA)}

The TGA curve for PVC alone, measured under inert atmosphere $\left(\mathrm{N}_{2}\right)$ is presented in fig. 2 . where it is compared to the profiles of composites. The total mass loss of PVC alone is about $62 \%$. In the temperature range $150-260{ }^{\circ} \mathrm{C}$ no significant mass losses are observed (approximately $2.4 \%$ ). Thermal degradation of PVC takes place in two stages as follows: in the first stage $\left(260-380^{\circ} \mathrm{C}\right)$, release of hydrochloric acid, followed by the formation of polyene structures, and in the second stage $\left(380-550^{\circ} \mathrm{C}\right.$ ) cyclization of the polyene structures with the formation of aromatic compounds. Thermal decomposition in the second step is represented by degradation of PVC backbone and, therefore, lower molecular weight compounds (and smoke) are produced [20-22].

After the addition of plasticizer and lubricant, the mass loss is about $14.7 \%$ for sample 2 (fig.2. a) and about $15 \%$ for sample 3 (fig.2. b) over a temperature range of 150-260 ${ }^{\circ} \mathrm{C}$. This increase in mass loss compared to neat PVC is due to plasticizer desorption. Desorption of a low molecular weight compound comprises two consecutive steps: diffusion of the plasticizer from the mass of the sample to its surface and evaporation from the surface. Further on, elimination of the hydrochloric acid from the composites begins in the range of $260-380^{\circ} \mathrm{C}$ and the mass loss increases significantly up to $56 \%$ for sample 2 and $57 \%$ for sample 3 . In this temperature range also begins the decomposition of the lubricants: stearic acid or stearate calcium (and also of Ca-Zn stabilizer, which is also a metal carboxylate). When adding reinforcing/fire-retardant agents, the loss of mass decreases and the decomposition temperature also presents higher maximum compared to samples 2 and 3, as summarized in tables 2 and 3. 

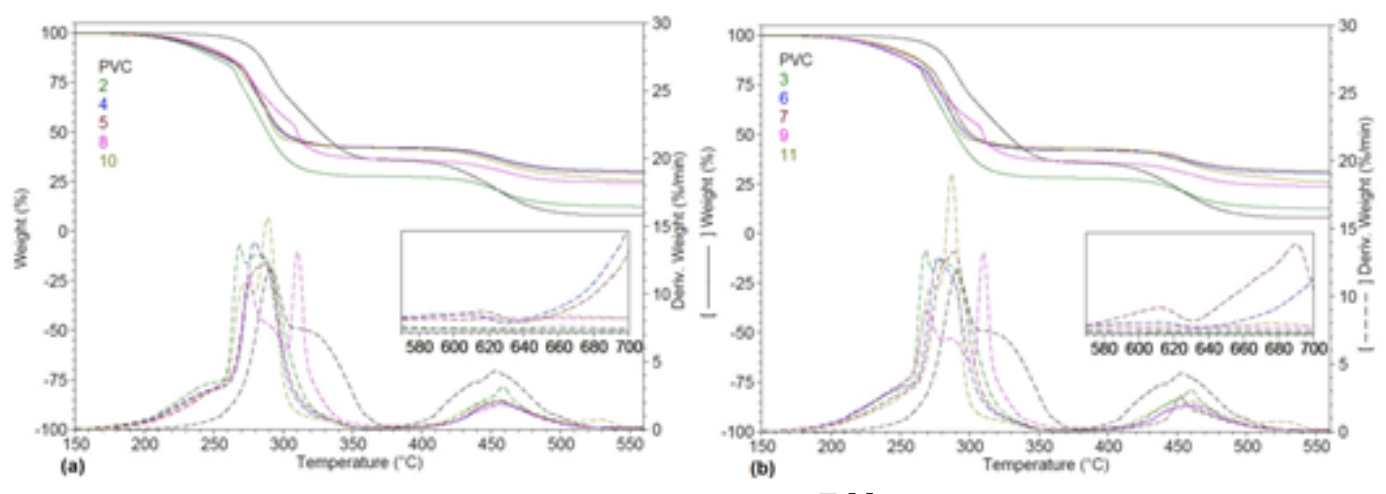

Fig. 2. Thermogravimetric analysis for PVC based composites with and without filler: a) PVC composites based on stearic acid as lubricant and b) PVC composites based on calcium stearate

Table 2

THERMOGRAVIMETRIC ANALYSIS FOR PVC BASED COMPOSITES WITH STEARIC ACID

\begin{tabular}{|c|c|c|c|c|c|c|}
\hline \multirow{2}{*}{ Sample } & $\mathbf{4 0 - 1 5 0 ^ { \circ } \mathrm { C }}$ & $150-\mathbf{2 6} 0^{\circ} \mathrm{C}$ & \multicolumn{2}{|c|}{$260-380^{\circ} \mathrm{C}$} & \multicolumn{2}{c|}{$380-\mathbf{5 5 0} \mathrm{C}$} \\
\cline { 2 - 7 } & Wt. loss & Wt. loss & Wt. loss & $\mathrm{T}_{2}$ range & Wt. loss & ${ }^{\circ} \operatorname{Tmax}_{3}$ \\
\cline { 2 - 7 } & $\%$ & $\%$ & $\%$ & ${ }^{\circ} \mathrm{C}$ & $\%$ & ${ }^{\circ} \mathrm{C}$ \\
\hline PVC & 0.01 & 2.42 & 61.78 & $291.0 / 330.2$ & 27.96 & 453.2 \\
\hline $\mathbf{2}$ & 0.12 & 15.71 & 56.63 & $268.8 / 281.0$ & 15.09 & 458.6 \\
\hline $\mathbf{4}$ & 0.10 & 13.52 & 44.14 & $279.4 / 290.4$ & 11.78 & 457.6 \\
\hline $\mathbf{5}$ & 0.07 & 12.82 & 45.19 & $276.7 / 287.2$ & 12.46 & 455.8 \\
\hline $\mathbf{8}$ & 0.06 & 11.72 & 52.16 & $293.3 / 310.6$ & 11.63 & 459.8 \\
\hline $\mathbf{1 0}$ & 0.13 & 12.20 & 45.91 & $272.3 / 288.8$ & 16.05 & 456.7 \\
\hline
\end{tabular}

Table 3

THERMOGRAVIMETRIC ANALYSIS FOR PVC BASED COMPOSITES WITH CALCIUM STEARATE

\begin{tabular}{|c|c|c|c|c|c|c|}
\hline \multirow{3}{*}{ Sample } & $40-150^{\circ} \mathrm{C}$ & $150-260^{\circ} \mathrm{C}$ & \multicolumn{2}{|c|}{$260-380^{\circ} \mathrm{C}$} & \multicolumn{2}{c|}{$380-550^{\circ} \mathrm{C}$} \\
\cline { 2 - 7 } & Wt. loss & Wt. loss & Wt. loss & $T_{2}$ range & Wt. loss & Tmax $_{3}$ \\
\cline { 2 - 7 } & $\%$ & $\%$ & $\%$ & ${ }^{\circ} \mathrm{C}$ & $\%$ & ${ }^{\circ} \mathrm{C}$ \\
\hline PVC & 0.01 & 2.42 & 61.78 & $291.0 / 330.2$ & 27.96 & 453.2 \\
\hline 3 & 0.09 & 14.12 & 57.82 & $279.6 / 292.3$ & 15.40 & 459.7 \\
\hline 6 & 0.08 & 14.07 & 43.79 & $277.6 / 289.8$ & 11.67 & 456.9 \\
\hline 7 & 0.08 & 11.38 & 46.29 & $278.2 / 288.9$ & 10.81 & 451.8 \\
\hline 9 & 0.08 & 14.58 & 49.16 & $286.3 / 310.1$ & 12.42 & 460.5 \\
\hline 11 & 0.13 & 10.51 & 46.04 & $273.3 / 287.3$ & 17.22 & 457.8 \\
\hline
\end{tabular}

PVC-based composites reinforced with calcium carbonate of $2 \mu \mathrm{m}$ (sample 4 lubricated with stearic acid and sample 6 lubricated with calcium stearate) show lower mass losses compared to samples with $1 \mathrm{~mm}$ calcium carbonate ( 5 and 7, respectively) and to control samples 2 and 3 with no reinforcing agent. Calcium carbonate, used as a reinforcing agent, reduces the emissions of hydrochloric upon composites degradation by trapping it in its structure to form $\mathrm{CaCl}_{2}$. It looks like calcium carbonate with larger particle sizes (VO2) absorbed higher amounts of hydrochloric acid, so the mass loss in the range of $260-380^{\circ} \mathrm{C}$ was lower compared to the small particle size of calcium carbonate (VO1). Hence, it was confirmed that calcium carbonate acts as a heat stabilizer by capturing hydrochloric acid, especially compared to the control sample 2, which presented much higher mass losses in this range. Yet, calcium stearate, besides his role as lubricant, has a co-stabilizing role, and hence, the decomposition maximum of PVC is shifted with $2{ }^{\circ} \mathrm{C}$ compared to the stearic acid-based PVC composites (fig.2. b). It can also be noted that stearic acid-based PVC composites also presented a shift for the decomposition maximum of PVC with $3^{\circ} \mathrm{C}$ relative to the control samples (fig.2. a).
The effect of fire retardants and smoke suppression agents is due to the Lewis acid catalyst. Lewis acids can favor PVC crosslinking to quickly form coal (ash) during burning. Thus, by this mechanism, metals from flame retardants (ATH and HMH) can favor PVC crosslinking during decomposition to increase coal formation [8-10]. Thermogravimetric analysis for samples with ATH and HMH (samples 8 and 10 with stearic acid-fig.2. a, and samples 9 and 11 with calcium stearate-fig.2. b) showed that the rate of polymer decomposition is slowed-down because the heat is absorbed by the decomposing metal hydroxide and the released water vapours dilute the flammable byproducts. Further on, the metal oxide residue acts as a thermal barrier and prevents the decomposition of the underlying polymer. From the results obtained for the samples containing ATH and $\mathrm{HMH}$, classified as flame retardants, it seems that the highest residue at $550{ }^{\circ} \mathrm{C}$ is obtained when HMH is used. The effect of ATH upon PVC decomposition is similar to the one obtained when calcium carbonate was used as reinforcing/ flame retardant agent according to the residues at $550^{\circ} \mathrm{C}$. Furthermore, the residues of the samples with $A T H$ and $\mathrm{HMH}$ at $700^{\circ} \mathrm{C}$, for measurements performed in air indicated that $\mathrm{HMH}$ was more efficient for suppressing the smoke emitted during combustion (table 4). 


\begin{tabular}{|c|c|c|}
\hline \multirow{2}{*}{ Sample } & \multicolumn{2}{|c|}{ Residue at $\mathbf{7 0 0}^{\circ} \mathbf{C}$} \\
\cline { 2 - 3 } & $\left(\mathbf{N}_{2}\right)$ & (Air) \\
\cline { 2 - 3 } & $\%$ & $\%$ \\
\hline $\mathbf{8}$ & 22.39 & 14.09 \\
\hline $\mathbf{1 0}$ & 23.63 & 11.98 \\
\hline $\mathbf{9}$ & 22.43 & 14.33 \\
\hline $\mathbf{1 1}$ & 24.29 & 12.00 \\
\hline
\end{tabular}

Table 4

RESIDUE FOR PVC

BASED COMPOSITES

WITH ATH AND HMH

\section{Differential scanning calorimetric analysis (DSC)}

Using DSC, the fluctuations in the glass transition temperature, $T_{\text {, }}$ of obtained composites were evaluated. The need for studying this behavior of PVC composites refers to the fact that decomposition temperature of neat PVC (above $160^{\circ} \mathrm{C}$ ) is lower than the melting temperature $\left(260^{\circ} \mathrm{C}\right)$. As a result, it is necessary to lower the $\mathrm{T}$ to prevent degradation of the polymer before processing, but also to establish a maximum temperature of processing and application of the composites [23-26].

In the DSC diagrams (fig.3. $a$ and b), the shift of the baseline following the glass transition for each PVC sample can be observed. The variations in the $T$ depend upon the type of filler but also upon the type of used lubricant. Neat PVC, without additives, shows a T of $85^{\circ} \mathrm{C}$. According to fig.3. $a$, the smallest $T$ is obtained for the samples with stearic acid, filled with calcium carbonate of $2 \mu \mathrm{m}$ ( sample $4, \mathrm{~T}_{\mathrm{a}}=-40.5^{\circ} \mathrm{C}$ ) and $\mathrm{HMH}$ (sample $10, \mathrm{~T}=-40.2^{\circ} \mathrm{C}$ ). PVC compositions with calcium stearate (fig.3. b) have slight higher $\mathrm{T}$ values relative to stearic acid-based composites. The low est values for $T$, in the samples series with calcium stearate were obtained for samples 6 and 7 , with calcium carbonate of $2 \mu \mathrm{m}\left(\mathrm{T}_{\mathrm{f}}=-39.4^{\circ} \mathrm{C}\right)$ and $1 \mu \mathrm{m}\left(\mathrm{T}_{=}=-39.1^{\circ} \mathrm{C}\right)$, respectively. Thus, the influence of the lubricant nature is perceivable as the T shifts towards lower values when stearic acid is used as lubricant $\left(-40.5^{\circ} \mathrm{C}\right)$. One explanation to this $\mathrm{T}$ decrease for samples with stearic acid can be due to the polarity of stearic acid, which seems to lead to strong interactions with the PVC matrix [26-28].

The effect of lubricants can be better seen from the summarized data on DSC in table 5. The widening of the T range (the difference between the Onsetand the End point) is narrower for nominated samples 4, 10 and 6, 7 containing either stearic acid or calcium stearate, respectively. It can be mentioned here that the heat capacity (Delta Cp) that accompanies glass transition was also in line with these observations, showing lower values, particularly for sample 4 with stearic acid as lubricant.

\section{Dynamic mechanical analysis (DMA)}

The effect of filler loading on the dynamic mechanical properties of PVC composites was studied. DMA was complementary on determining the storage modulus, loss modulus at maximum value and the dynamic loss tangent at maximum value [29-30]. When the storage modulus $\left(E^{\prime}\right)$ increases with the filler loading usually indicates that mobility of the polymer chain is decreased in the presence of the reinforcing/flame-retardant agents. In this study, it was observed that filler incorporation into the PVC matrix may decrease the mechanical damping of PVC (fig. 4. a and $b$ ). The height (peak intensity) and position of $E^{\prime}$ peaks for the composite samples varied with type of filler.

The values of $E^{\prime}$ were determined for each sample at a temperature of $-70{ }^{\circ} \mathrm{C}$. The highest $\mathrm{E}^{\prime}, 7583 \mathrm{MPa}$, was attained by sample 11 (with HMH as filler and calcium stearate as lubricant) while the lowest $\mathrm{E}^{\prime}, 4799 \mathrm{MPa}$, was

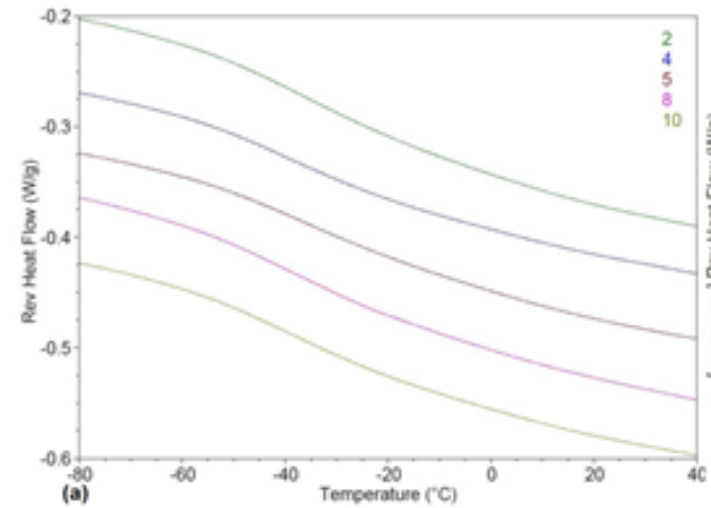

(a) (b)

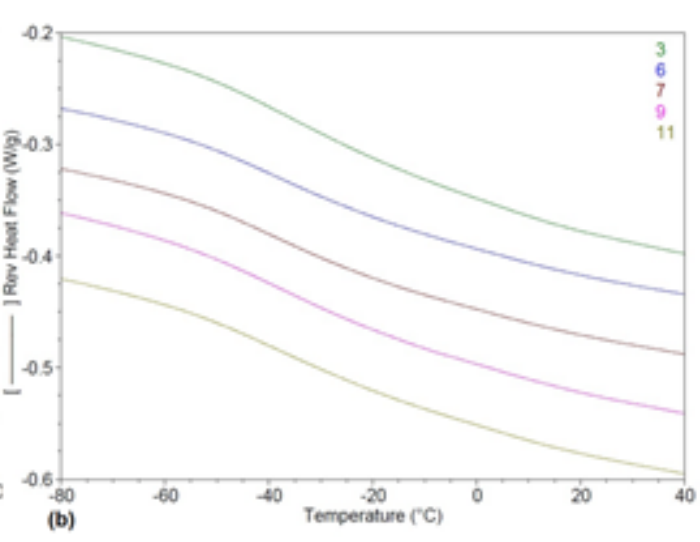

PVC - Glass Transition Experiment

\begin{tabular}{|c|c|c|c|c|}
\hline \multirow{2}{*}{ lst Heating } & \multicolumn{4}{|c|}{ PVC - Glass Transition Experiment } \\
\hline $\begin{array}{c}\text { Reversible Heat } \\
\text { Flow }\end{array}$ & Onset & Tg & End & Delta Cp \\
\cline { 2 - 5 } & ${ }^{\circ} \mathrm{C}$ & ${ }^{\circ} \mathrm{C}$ & ${ }^{\circ} \mathrm{C}$ & $\mathrm{J} /\left(\mathrm{g} \cdot{ }^{\circ} \mathrm{C}\right)$ \\
\hline 2 & -54.2 & -36.3 & -4.1 & 0.358 \\
\hline 4 & -55.7 & -40.5 & -11.0 & 0.285 \\
\hline 5 & -54.0 & -36.3 & -3.7 & 0.312 \\
\hline 8 & -55.7 & -39.2 & -8.7 & 0.323 \\
\hline 10 & -56.2 & -40.2 & -8.2 & 0.322 \\
\hline 3 & -53.8 & -35.8 & -2.4 & 0.373 \\
\hline 6 & -55.2 & -39.4 & -7.3 & 0.309 \\
\hline 7 & -55.4 & -39.1 & -8.9 & 0.303 \\
\hline 9 & -55.2 & -37.8 & -6.6 & 0.327 \\
\hline $\mathbf{l l}$ & -55.2 & -38.8 & -4.7 & 0.328 \\
\hline
\end{tabular}

http://www.revmaterialeplastice.ro
Fig. 3. Differential scanning calorimetry for PVC based composites with and without filler: a) PVC composites based on stearic acid as lubricant and b) PVC composites based on calcium stearate 


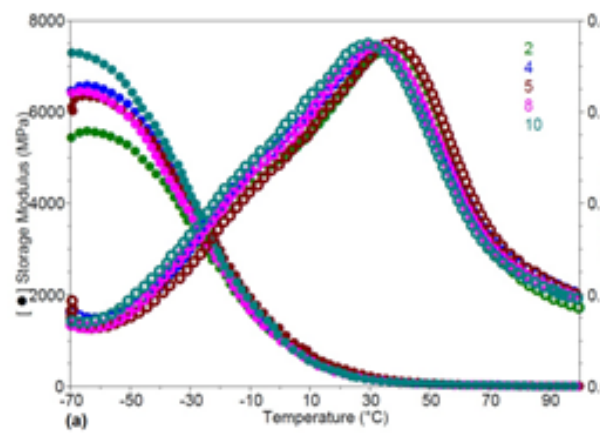

(a)

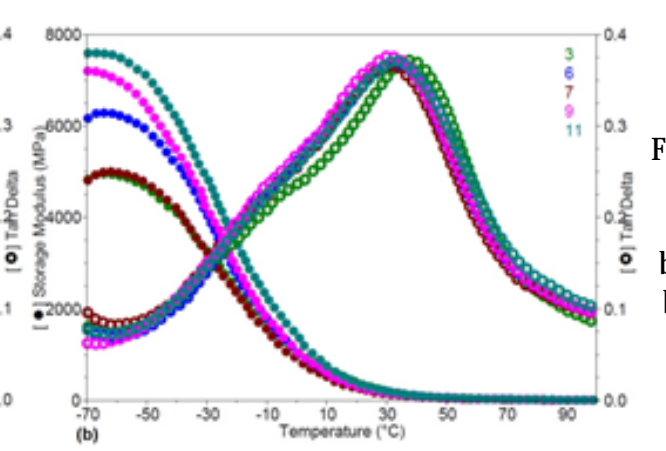

Fig. 4. Dynamic mechanical analysis for PVC based composites with and without filler: a) PVC composites based on stearic acid as lubricant and b) PVC composites based on calcium stearate characteristic of sample 7 (with calcium carbonate of 1 $\mathrm{mm}$ and calcium stearate as lubricant). The registered values of $E^{\prime}$ for the control samples 2 and 3 were $5426 \mathrm{MPa}$ and $4829 \mathrm{MPa}$, respectively. A clear comparison of characteristics can be extracted from table 6 . The values of $E^{\prime}$ decreased, while the $E^{\prime \prime}$ values gradually increased. Hence, at temperatures above $-20^{\circ} \mathrm{C}$, all the investigated composites presented high elasticity. The filler incorporation increased the storage and loss modulus, which explained the higher heat dissipation in the PVC composites compared with neat PVC, confirming that the new formulations of PVC are flexible.

\section{Tensile strength and elongation at break}

To evaluate the quality of flexible PVC composites in industrial application, one of the mostimportant properties is tensile strength. It can be observed form fig. 5. a, b, c and d that elongation atbreak and tensile strength of testsamples decreased with the filler loading for each type of PVC composite. This decrease in mechanical properties is attributed to restriction of polymer chain movements [3132]. For control sample 2 and 3 with no filler, the highest mechanical properties values are obtained. Yet, depending on the subsequent use of the composites certain properties are required.

Stearic acid composites (fig.5. a and b) exhibit large variations in mechanical properties, due to the size of calcium carbonate and the capacity of the lubricant to allow homogenization during composites preparation. Sample 5 with $1 \mathrm{~mm}$ calcium carbonate attained the highest tensile strength and the lowest elongation from the series of composites with stearic acid and fillers, which is bizarre but maybe due to the low mobility of the polymer. Calcium carbonate of $2 \mu \mathrm{m}$ (sample 4) is better embedded in the material and more elastic samples are obtained. For the series with calcium stearate (fig.5. c and d) it seems that the size of the calcium carbonate did not affect the mechanical properties significantly. This means that the lubricant also plays an important role in the compounding of the samples. Calcium stearate ensures more uniform mechanical properties due to better compatibility with calcium carbonate, and hence, the size of this filler does not affect the tensile strength and elongation at break.

When the reinforcing/flame-retardant agent is added to the composites, the tensile strength and elongation at break decrease continuously even more for the PVC composites with stearic acid as lubricant (fig.5. $a$ and b), with exception for sample 5 . For the calcium stearatebased composite (fig.5. c and d), adding ATH (sample 9) in the formulation leads to similar values to that of samples 6 and 7 with calcium carbonate, meaning elongation at break $432 \%$ and tensile strength of $16 \mathrm{~N} / \mathrm{mm}^{2}$. It can be noted that $\mathrm{HMH}$ based composites, samples 10 and 11 , presented the lowest values for tensile strength and elongation atbreak (except for sample 5) in both series of composites.

Limited oxygen index (LOI)

Table 6

DMA RESULTS FOR PVC COMPOSITES

\begin{tabular}{|c|c|c|c|c|c|c|c|c|c|c|c|}
\hline \multirow{4}{*}{ 言 } & \multirow{2}{*}{\multicolumn{2}{|c|}{$\begin{array}{c}\text { Loss Modulus } \\
\text { E"-Peak }\end{array}$}} & \multirow{2}{*}{\multicolumn{2}{|c|}{$\begin{array}{c}\text { Tan Delta } \\
\text { Tan } \delta\end{array}$}} & \multicolumn{7}{|c|}{ Storage Modulus } \\
\hline & & & & & \multirow{3}{*}{$\begin{array}{c}\text { Onset } \\
{ }^{\circ} \mathrm{C}\end{array}$} & \multirow{3}{*}{ Midpoint ${ }^{\circ} \mathrm{C}$} & \multirow{3}{*}{$\begin{array}{c}\text { End } \\
{ }^{\circ} \mathrm{C}\end{array}$} & \multicolumn{4}{|c|}{$\mathbf{E}^{\prime}, \mathbf{M P a} / \mathbf{T e m p e r a t u r e}^{\circ}{ }^{\circ} \mathrm{C}$} \\
\hline & Temp. & Height & Temp. & Height & & & & & & & \\
\hline & ${ }^{\circ} \mathrm{C}$ & $\mathbf{M P a}$ & ${ }^{\circ} \mathrm{C}$ & $\mathbf{M P a}$ & & & & -70 & 0 & 30 & 100 \\
\hline 4 & -31.23 & 604.2 & 32.55 & 0.369 & -45.26 & -29.43 & -2.22 & 6312 & 1014 & 172.8 & 8.229 \\
\hline 5 & -29.07 & 541.1 & 37.17 & 0.3748 & -43.66 & -23.06 & 4.29 & 6165 & 1258 & 222.6 & 8.54 \\
\hline 8 & -33.69 & 580 & 31.62 & 0.3713 & -51.6 & -40.02 & 2.31 & 6414 & 985.3 & 149.6 & 8.01 \\
\hline 6 & -30 & 571.6 & 32.55 & 0.3682 & -46.29 & -28.72 & -0.85 & 6156 & 1018 & 171.4 & 8.109 \\
\hline 7 & -31.84 & 484.4 & 30.7 & 0.3653 & -42.8 & -36.48 & 2.45 & 4799 & 902.2 & 135.1 & 7.338 \\
\hline 9 & -32.46 & 634.7 & 30.7 & 0.3751 & -51.86 & -24.14 & -1.27 & 7194 & 1054 & 152.4 & 7.92 \\
\hline 11 & -31.84 & 705.1 & 32.86 & 0.3708 & -47.53 & -25.9 & 1.77 & 7583 & 1392 & 194 & 8.849 \\
\hline
\end{tabular}



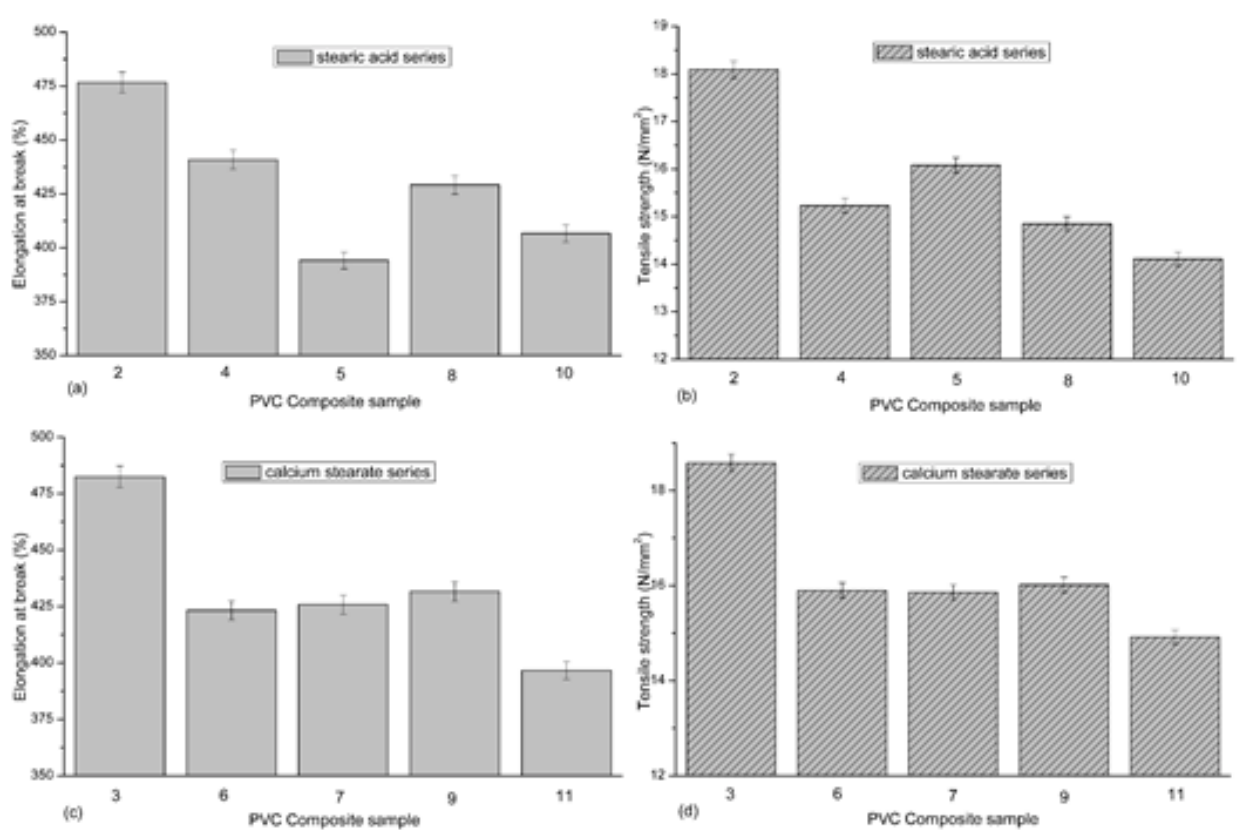

Fig. 5. Mechanical properties for the two PVC series of composites: a) Elongation at break for the stearic acid-based composites; b) Tensile strength for the stearic acid-based composites; c) Elongation at break for the calcium stearate-based composites; d) Tensile strength for the calcium stearate-based composites

The minimum oxygen concentration in a variable oxygen/nitrogen atmosphere is known as the limiting oxygen index (LOI) that will just support ignition of a sample. This test is generally recognized to be useful for quality control purposes [33-36]. The LOI test is extensively valuable and used to determine the flammability of polymeric materials. Greater fire retardation is given by a higher measured value of LOI. Values of LOI greater than 21 indicate that composites do not burn immediately in air.

The LOI values of tested PVC composites are shown in figure 6 . $a$ and $b$. The results indicated that the minimum amount of oxygen for the ignition of sample had an increasing trend when using flame retardants in the composition. For control samples 2 and 3 with no filler in the composition the LOI value is around 21 , so the sample can ignite in air easily. As expected, when adding filler in the composition, the LOI value increase.

Calcium carbonate acts as scavenger during ignition, forming calcium chloride with the hydrochloric acid released during ignition. This process hinders the reaction betw een oxygen and PVC molecules, and implicitly, leads to high LOI values [6, 37]. But, the flame-retardation effect of calcium carbonate is limited. In a study made by Xu et al., calcium carbonate showed little or no flame-retardant effect on PVC and for improving the efficiency, the authors coated $\mathrm{CaCO}_{3}$ with $\mathrm{SnO}_{2}$ [38]. Herein, the LOI values increased for the samples filled with calcium carbonate in both series of composites relative to the control samples 2 and 3 . For the $2 \mathrm{~mm}$ calcium carbonate composites, i.e. samples 4 and 6 , the values were above $23 \%$, while for the ones with $1 \mu \mathrm{m}$ calcium carbonate, i.e. samples 5 and 7 , between 22.2 and $22.6 \%$. The results obtained for the two types of calcium carbonate fillers are in agreement with the thermal analyses, which indicated a higher capacity of the $2 \mu \mathrm{m}$ calcium carbonate to adsorb hydrochloric acid.

LOI values of PVC based composites increased even more when ATH and HMH were used in the PVC composite formulation. ATH and HMH decompose endothermically and release water. The endothermic decomposition of water hijacks the heat needed for polymer burning and retards the flame. This phenomenon is also referred as sink phenomenon. Water released during decomposition of these flame retardants dilutes the gases and forms water vapour barriers that retains the oxygen, which otherwise ignites and supports the flame [8-10, 39-40]. The highest LOI value were achieved for ATH formulations meaning, sample 8 with stearic acid as lubricant $(25.8 \%)$ and sample 9 with calcium stearate as lubricant $(26 \%)$. It is also important to point out that PVC composites, with calcium stearate as lubricant, presented superior LOI values compared to the ones with stearic acid.

\section{Contact angle (CA)}

Contact angle (CA) is the most important parameter used to quantify the wettability of solid surfaces. In this respect, the need to preserve or enhance the hydrophobicity of the composite materials, which are used in out-door applications, refers to stability in moist environment and preservation of flame-retardant properties on long term [41]. Conventionally, the contact angle describes the

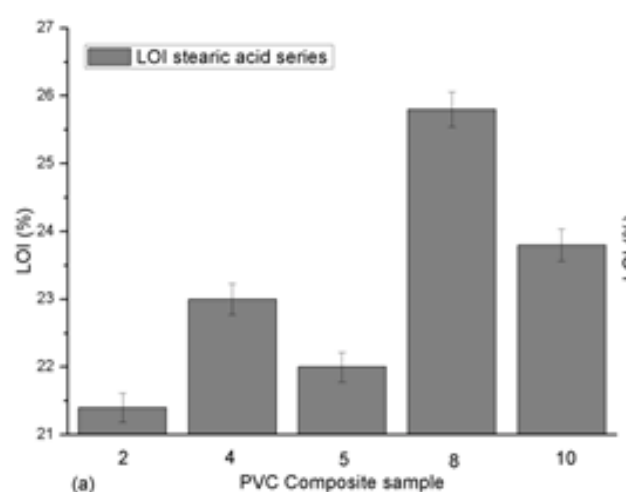

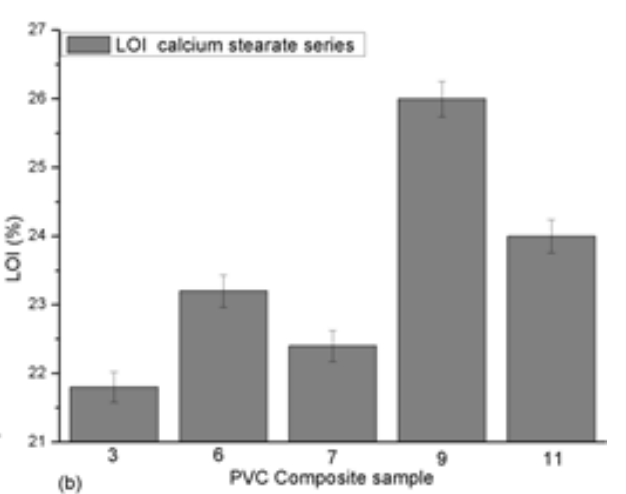

Fig. 6. LOI values for the two PVC series of composites a) stearic acidbased composites, and b) calcium stearate-based composites 


\begin{tabular}{|c|c|c|c|}
\hline $\begin{array}{c}\text { Samples with } \\
\text { Stearic acid }\end{array}$ & Contact angle (o) & $\begin{array}{c}\text { Sample with Calcium } \\
\text { stearate }\end{array}$ & $\begin{array}{c}\text { Contact } \\
\text { angle (o) }\end{array}$ \\
\hline $\mathbf{2}$ & 112.90 & $\mathbf{3}$ & 114.38 \\
\hline $\mathbf{4}$ & 90.87 & $\mathbf{6}$ & 98.95 \\
\hline $\mathbf{5}$ & 104.17 & $\mathbf{7}$ & 108.70 \\
\hline $\mathbf{8}$ & 106.39 & 9 & 114.57 \\
\hline $\mathbf{1 0}$ & 105.37 & $\mathbf{l l}$ & 114.21 \\
\hline
\end{tabular}

Table 7

CONTACT ANGLE VALUES FOR PVC COMPOSITES
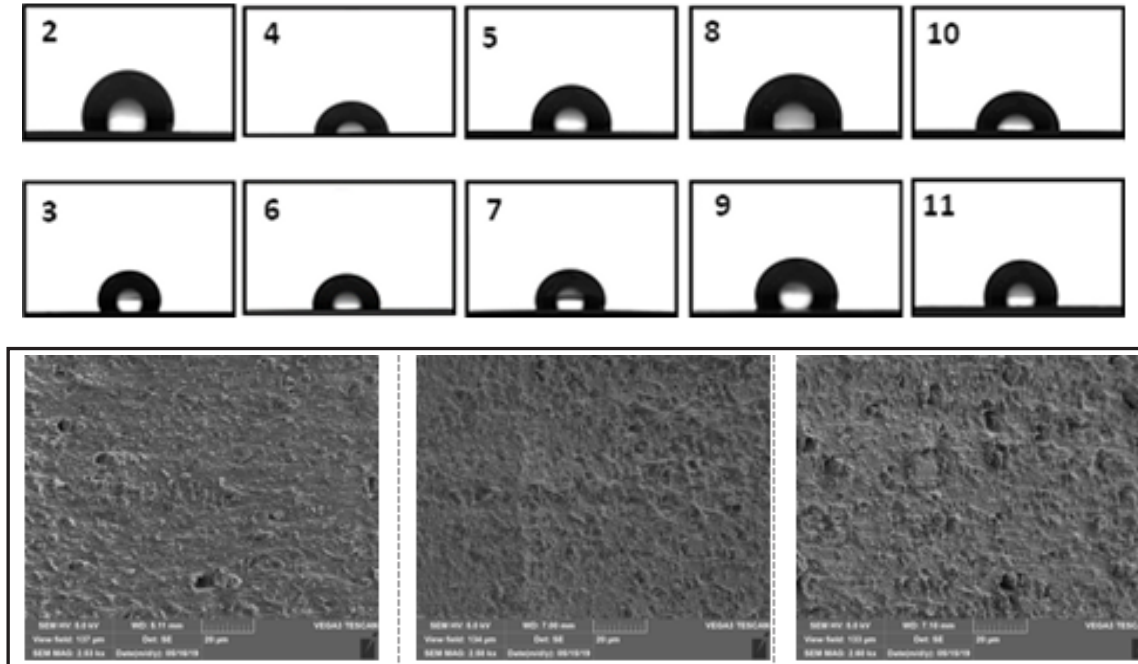

a) Sample 5

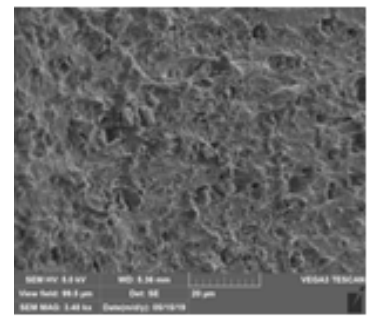

b) Sample 7

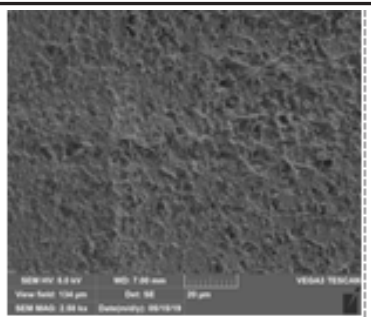

Sample 8

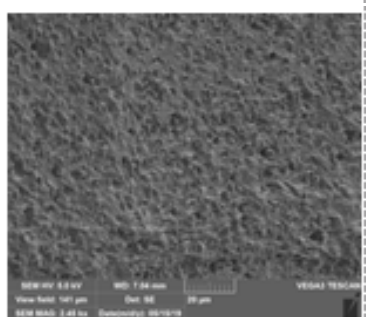

Sample 9

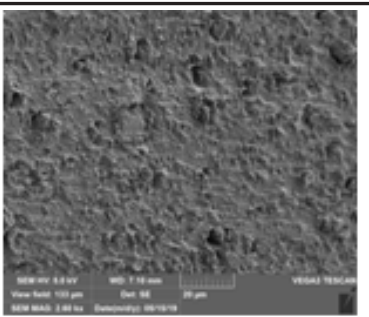

Sample 10

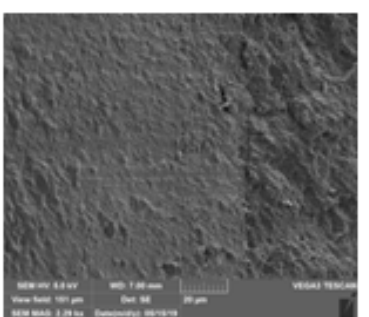

Sample 11

Fig. 7. Contact angle values for the two PVC series of composites: with stearic acid (samples 2, 4, 5, 8 and 10) and with calcium stearate (samples 3, 6, 7, 9 and 11)

Fig. 8. SEM analysis for the two PVC series of composites a) stearic acid-based composites, and b) calcium stearate-based composites

behaviour of a liquid droplet on a solid surface in air, and is defined as the angle between the tangent at the three phase point and the solid surface. The degree of wetting when a solid and liquid interact is indicated by wettability studies, which usually involve the measurement of contact angles as the primary data. High wettability corresponds to small contact angles $\left(<<90^{\circ}\right)$, while large contact angles $\left(>>90^{\circ}\right)$ correspond to low wettability or hydrophobicity [42-45].

Table 7 reflects a viable agreement of contact angles with the samples composition in terms of presence or absence of reinforcement material and lubricant. It was observed that the samples without reinforcing or flame retardant material (samples 2 and 3 ) attained high contact angles, due to the low or complete lack of $\mathrm{OH}$ groups (fig. 7). When introducing calcium carbonate (samples 4,5 and 6, 7 respectively), the wettability increases for both series of composites due to the water adsorption capacity of the filler, while the contact angles of PVC composites with ATH and HMH (samples 8 and 10, and 9 and 11, respectively) are slight higher.

The explanation suggested by some authors is related to the hydrophilic surface of ATH and $\mathrm{HMH}$, which becomes partly hydrophobic after lubrication and compounding in the PVC matrix, leading to lower surface energy [43]. Yet, it seems like the particle size of the reinforcing agent also plays an important role on lubrication and further on the hydrophobicity of surfaces. In figure 7, for instance, the composites with calcium carbonate of $2 \mu \mathrm{m}$ particle size (samples 4 and 6) presented lower contact angles than the ones with $1 \mu \mathrm{m}$ particle sized calcium carbonate (samples 5 and 7). Herein, it can also be observed that calcium stearate led to composites with higher hydrophobicity when using ATH or HMH (samples 9 and 11 , respectively), when compared to the stearic acid-based composite series. Therefore, the waterproof property of composites is somewhat enhanced when using calcium stearate.

\section{Scanning electronic microscopy (SEM)}

The final step to establish an optimum formulation for flame-retardant flexible polyvinylchloride composites was scanning electronic microscopy of PVC composites. As it can be seen in figure 8, calcium stearate used as lubricant led to more homogenous composites and the presence of macropores was reduced, compared to the series of samples with stearic acid. The composites with $\mathrm{CaCO}_{3}$ of $1 \mu \mathrm{m}$ (samples 5 and 7) presented macropores and agglomerations.

The samples with $\mathrm{HMH}$ (sample 10 with stearic acid and sample 11 with calcium stearate) were rather homogenous, presenting some zones with smooth 
surfaces. Nevertheless, the samples with ATH (sample 8 with stearic acid and sample 9 with calcium stearate) presented a more discrete surface arrangement with a better dispersion of solids and more homogenously dispersed macropores, particularly for sample 9.

\section{Conclusions}

New formulations of PVC composites with potential applications in the industry for electrical wires and cables were prepared and characterized. Calcium carbonate with particle size of 1 and $2 \mu \mathrm{m}$, which is a cheap version of flame-retardant fillers (also called reinforcing agents), has proven to be proper for decreasing the T value of PVC and to contribute to the optimization of mechanical properties referring to elasticity, elongation at break and tensile strength of composites. Yet, the flammability of thereof was high compared to that of control samples. HMH-based composites presented medium properties, comparable to those of calcium carbonate, but exhibited higher fire retardation. ATH, seemed to be the most proper filler for preparing flame-retardant PVC composites, leading to low Tg values of PVC, good mechanical properties, flexibility and high limiting oxygen indexes (comparable to that of HMH-based PVC composites). Comparing the composites from the point of view of the two used lubricants, stearic acid and calcium stearate, it can be concluded that calcium stearate ensures better compatibility of components, enhanced hydrophobicity and leads to more homogenous PVC composites, as confirmed by SEM analysis and also other studies [46-49].

Acknowledgements: This work was supported by a grant of the Ministry of Research and Innovation, PN 18.22.04.02/2018 (OXOBIOPOL), contractno. 21N/2018, and a grant awarded by UEFISCDI in framework of the PCCDI competition, contract no. 70PCCDI/2018 SECURE-NET.

\section{References}

1.VRANDECIC N. S., KLARIC I., ROJ E U., Effect of Ca/Zn stabiliser on thermal degradation of poly(vinyl chloride)/chlorinated polyethylene blends, Polym Degrad Stab., 74, 2001, p. 203 - 212.

2.ELNAGGAR M. Y., FATHY E. S., MEDHAT M. H., Investigation of Physicomechanical properties of flexible poly (vinyl chloride) filled with antimony trioxide using ionizing radiation, Environ Technol, 2018, https://doi.org/10.1080/09593330.2018.1461247

3.LEVCHIK S. V., WEIL E. D., Overview of the recent literature on flame retardancy and smoke suppression in PVC, Polym Adv Technol., 16,2005 , p. 707-716.

4.ZHANG L., LI J., DING X., Research of the properties of flameretardant flexible PVC, American J ournal of Materials Research, 1, 2014, p. 20-25.

5.WYPYCH G., PVC Degradation \& Stabilization. 3rd ed. Toronto, ChemTec Publishing, 2015.

6.LIU P., ZHAO M., GUO J., Thermal stabilities of Poly(vinyl chloride)/ calcium carbonate $\left(\mathrm{PVC} / \mathrm{CaCO}_{3}\right)$ composites, J. Macromol. Sci B, 45, 2006, p. 1135-1140.

7.WEIL E. D., LEVCHIK S., MOY P., Flame and smoke retardants in vinyl chloride polymers - Commercial usage and current developments, J. Fire Sci., 24, 2006, p. 211-236.

8.*** Environmental, health and safety issues in the coated wire and cable industry. University of Massachusetts Lowell. 2002, https:// www.turi.org/TURI_Publications/Toxics_Use_Reduction_for Industrial_Sectors/Wï-re_Cable/Environmental_Health_and_Safety Issues_in_the_Coated_W Wire_and_Cable_Industry._2002, accessed in $110 \operatorname{ct}^{-} 20 \overline{1} 8$.

9.YILMAZH., ÇELIK A., Use of Turkish huntite/hydromagnesite mineral in plastic materials as a flame retardant, Polym Compos., 31, 2010, p. $1692-1700$.

10.WALKER J. K., HO W. K., MITTLEMAN M. L., Smoke suppression in PVC plenum cable jackets, International Wire \& Cable Symposium,
Proceedings of the 54th IWCS/Focus, 2005, https://www.academia.edu/ 5211667/Smoke_Suppression_in_PVC_Plenum_Cable_Jackets, accessed in 18 Sep 2018.

11.MIHAJ LOVICE., CVETANOVIC S., DORDEVIC A., KRSTIC I., POPOVIÆE D., PVC material fire retardants, Facta Universitatis, Series Working and Living Environmental Protection, 7, 2010, p. 1 - 11.

12.QU H., WU W., JIAO Y., XU J., Thermal behavior and flame retardancy of flexible poly(vinyl chloride) treated with $\mathrm{Al}(\mathrm{OH})_{3}$ and ZnO, Polym Int., 54, 2005, p. 1469-1473.

13.PATRICK S., PVC compounds and processing, United Kingdom: Rapra Technology Limited, 15, ISBN 978-1-8595-7472-0, 2004.

14.HOLLINGBERY L., Decomposition and fire retardancy of naturally occurring mixtures of huntite and hydromagnesite, 2011, https:// core.ac.uk/download/pdf/340558.pdf, accessed in 15 Aug 2018.

15. HOLLINGBERY L. A., HULL T.R., The thermal decomposition of huntite and hydromagnesite -A review, Thermochim Acta, 509, 2010, p. 1-11.

16.GRAND A. F., WILKIE C. A., Fire retardancy of polymeric materials, Marcel Dekker Inc, New York, ISBN 978-1-4200-8399-6, 2000.

17.WILKIE C. A., MORGAN A. B., Fire retardancy of polymeric materials, 2nd ed. Florida: CRC Press, 2010, p.15-42.

18.DUFTON P. W., Functional additives for the plastics industry: Trends in use, Rapra Technology Limited, U.K, 1998.

19.DAVALLO M., PASDAR H., The influence of a variety of plasticisers on properties of Poly (vinyl chloride), Adv Appl Sci Res., 3, 2012, p. 1900-1904.

20.KARAYILDIRIM T., YANIK J., YUKSEL M., SAGLAM M., VASILE C., BOCKHORN H., The effect of some fillers on PVC degradation, J. Anal. Appl. Pyrolysis, 75, 2006, p. 112-119.

21.IVAN B., Thermal stability, degradation, and stabilization mechanisms of Poly(vinyl chloride), Polymer Durability; Advances in Chemistry, 1996, 10.1021/ba-1996-0249.ch002.

22.ZBYNEK M., Thermal decomposition of Polyvinyl chloride and of its low-molecular-weight model compounds, J. Macromol. Sci.-Revs. Macromol. Chem., 10, 1974, p. 263-292.

23.UNAR I. N., SOOMRO S. A., AZIZ S., Effect of various additives on the physical properties of Polyvinylchloride resin, J. Anal. Environ. Chem., 11, 2010, p. 44 - 50.

24.MARTIN T. M., YOUNG D. M., Correlation of the glass transition temperature of plasticized PVC using a lattice fluid model, Polym J., 44, 2003, p. 4747-4754.

25.BURDONOV A. E., Barakhtenko V. V., Zelinskaya E. V., Yudin V. E., Elokhovskii V.Y., Dynamic mechanical analysis of composite materials based on polyvinyl chloride and thermal power station waste, Int. J. Polym. Sci., 42, 2015, p. 53-57.

26.ROSEN S. L., BRAZEL C. S., Fundamental principles of polymeric materials, 3rd ed., John Wiley \& Sons Inc, New Jersey, ISBN: 9780470505427, 2012.

27.ALLSOPP M. W., VIANELLO G., Poly(Vinyl Chloride), Ullmann's Encyclopedia of Industrial Chemistry, Wiley-VCH, Weinheim, 2012, doi:10.1002/14356007.a21_717.

28.ELVERS B., Ullmann's Polymers and Plastics: Products and Processes, Wiley-VCH, Weinheim, 1, 2016.

29.CHEN N., WAN C., ZHANG Y., ZHANG Y., Effect of nano-CaCO on mechanical properties of PVC and PVC /Blendex blend, Polym Test, 23, 2004, p. 169-174.

30.GIL N., SASKA M., NEGULESCU I., Evaluation of the effects of biobased plasticizers on the thermal and mechanical properties of Poly(vinyl chloride), J Appl Polym Sci., 102, 2006, p. 1366-1373.

31.AWADW. H., GÜNTER B. , DAPHNE B., WOUTER L.I. , PONUSA S. , GASCO M. M., MANIAS E. , WILKIE Ch. A., Material properties of nanoclay PVC composites, Polym., 50, 2009, p. 1857-1867.

32.GAO F., Advances in Polymer Nanocomposites: Types and Applications, Woodhead Publishing Limited, U.K, ISBN: 9780857096241 , 2012.

33.NAKAGAWA Y. A., Note on an Oxygen Index test on Electric Cables, J Fire Sci., 1994, https://doi.org/10.1177/073490419401200603.

34.SUZANNE M., DELICHATSIOS M., ZHANG I., Prediction of the limiting oxygen index using simple flame extinction theory and material 576 http://www.revmaterialeplastice.ro
MATERIALE PLASTICE $\bullet 56$ No. $3 \bullet 2019$ 
properties obtained from bench scale measurements, Fire Saf Sci., 10, 2011, p. 375-387.

35.NELSON N., AHMAD N., ZWICKEY J ., Critical testing and properties of cable and wire markers,http://www.techni-tool.com/site/ ARTICLE_LIBRARY/Brady\%20-\%20Critical\%20Testing\%20and\%20 Properties\%20f\%20Cable\%20and \%20W ire\%20Markers.pdf, accessed in 17 Nov 2018.

36.HORROCKS A. R., SMART G., NAZARE S., KANDOLA B., PRICE D., Quantification of zinc hydroxystannate and stannate synergies in halogen-containing flame-retardant polymeric formulations, J Fire Sci., 28, 2009, p. 217-248.

37.MATTHEWS G., PLEMPER G. S., Effects of calcium carbonate fillers on the behaviour of PVC in fires, Brit Polym J., 1981, https://doi.org/ 10.1002/pi.4980130105.

38.XU J., JIAO Y., ZHANG B., QU H., YANG G., Tin Dioxide coated calcium carbonate as flame retardant for semirigid Poly(vinyl chloride), J Appl Polym Sci., 101, 2006, p. 731-738.

39.BEYLER C. L., HIRSCHLER M. M., Thermal decomposition of polymers. SFPE handbook of fire protection engineering 3rd ed., National Fire Protection Association, USA, 2002, p. 111-131.

40.BLAZSO M., JAKAB E., Effect of metals, metal oxides, and carboxylates on the thermal decomposition processes of poly(vinyl chloride), J Anal Appl Pyrolysis, 49, 1999, p. 125-143.

41.CHENG X. W., LIANG C. X., GUAN J. P., YANG X. H., TANG R. C., Flame retardant and hydrophobic properties of novel sol-gel derived phytic acid/silica hybrid organic-inorganic coatings for silk fabric, Appl Surf Sci, 427, 2018, p. 69-80.
42.ALDOBIANI M., AL-MAHAQERI H. M., MAREAI A. S., ALGEREDI O., BORA P., Dr. KANNA A. R., Determination of Contact Angle of Various Fluids In oil Industry, IRJ ES 7, 2018, p. 61-63.

43.LIU G., ZHOU B., LI Y., QI T., LI X., Surface properties of superfine alumina trihydrate after surface modification with stearic acid, Int J Min Met Mater, 22, 2015, p. 537.

44.ZHAO T., J IANG L., Contact angle measurement of natural materials, Colloids Surf B Biointerfaces, 161, 2018, p. 324-330.

45.HUANG F., WEI Q., WANG X., XU W., Dynamic contact angles and morphology of PP fibres treated with plasma, POLYM TEST., 25, 2006, p. 22-27.

46. RABINOVITCH E. B., LACATUS E., SUMMERS J. W., The lubrication mechanism of calcium stearate/paraffin wax systems in PVC compounds, J Vinyl Addit Techn, 1984, https://doi.org/10.1002/ vnl.730060303.

47. MIRCI, L. E., BORAN, S., Plasticizers and lubricants of adipic ester type with complex structure, Mat Plast, 44, no. 4, 2007, p. 383-392.

48. CAILEAN, A., SUTIMAN, D., CREPESCU, I., CROITORU, C., MARECI, $D$, Thermal behaviour prediction of rigid polyvinyl chloride, Mat Plast, 44, no. 4, 2007, p. 294-297.

49. MUTHUPOONGODI, S., MITU, L., LINDA, T., SHAJAN, X. S., BALAKUMAR, S., Facile recoverable, reusable and efficient heterogeneous photocatalyst. Preparation and characterization of $\mathrm{V}_{2} \mathrm{O}_{5}$ added $\mathrm{TiO}_{2}$ polymer NCs, Rev Chim. (Bucharest), 69, no. 10, 2018, p. 2662-2668.

$\overline{\text { Manuscript received: } 12.06 .2019}$ 